\title{
Developing Mathematical Literacy, Based on Elemental Software and Academic Tools Development
}

\author{
Oscar H. Salinas ${ }^{1}$, Angel Estrada Arteaga ${ }^{2}$, Martha E. Luna ${ }^{1}$, \\ Marco A. Amado González ${ }^{1,2}$ \\ ${ }^{1}$ División Académica de Tecnologías de la Información y Comunicación \\ ${ }^{2}$ Centro de Desarrollo de Software, Universidad Tecnológica Emiliano Zapata del Estado de Morelos, \\ Emiliano Zapata, Morelos, México \\ Email: oscarsalinas@utez.edu.mx, angelestrada@utez.edu.mx
}

Received May $16^{\text {th }}$, 2013; revised June $16^{\text {th }}$, 2013; accepted June $23^{\text {rd }}$, 2013

Copyright (C) 2013 Oscar H. Salinas et al. This is an open access article distributed under the Creative Commons Attribution License, which permits unrestricted use, distribution, and reproduction in any medium, provided the original work is properly cited.

\begin{abstract}
This report describes the procedure to develop mathematical literacy through learning basic mathematical concepts, and applying the acquired knowledge for the development of elemental software to be used as academic tool. Basic operations with matrix were performed using open and commercial sources software. A simple and basic matrix calculator were developed integrating mathematical concepts and software development skills, and the deliverable was a calculator developed on Java platform. The procedure started from a traditional classroom explanation; worked on calculus worksheet, solving some academic problems about addition, subtracted product of two matrix, following by the use of some commercial software, and finally the development of the own academic tool. These works were developed into the frame of competency based education system.
\end{abstract}

Keywords: Mathematical Concepts; Didactic Tools; Software Development; Competency

\section{Introduction}

Mathematics has been a tough topic to learn and even the worst to teach traditionally. Most of the people think that is a very difficult topic to overcome, because they think it is a topic just for people with high intellectual coefficient. Therefore, the professors face a big dare of teaching mathematics topics. Besides in México, professors of higher education face up the problem that most of the times young students coming from basic education don't have the basic mathematics concepts. Sometimes the problem starts since the definition of Mathematics is not well know of being described. This has been changed trough the time (Devlin, 1998), but the current mean, given from mathematicians, is "the science of patterns" (Devlin, Mathematics: The Science of Patterns, 1996; The language of Mmathematics, Making the Invisible Visible, Devlin, 1998; Sawyer, 1995; Wittman, 2000) and this definition gives more information about what mathematics is. Competency based education system matches very well with the so called four general objectives of teaching mathematics: "mathematising", exploring, reasoning and communication. It means students learning mathematics, would have a deeper understanding on them, when they face the dare of communicating what they have learned. It has been established that the important things are not the finished products but the short and long term ones (Wittman, 2000), however academic products are not included inside of this statement, according with the authors understanding. Competency based education system was implemented at
Universidad Tecnológica Emiliano Zapata del Estado de Morelos (UTEZ), since 2009, following the Tuning Educational Structures for Latin America (Latina, 2007). Inside the framework of competency based education, professors have to identify the different learning mechanisms of students in the aim that all of them get the same level of knowledge. It has been demonstrated that there are six fundamental competencies about Mathematics, to a person who gets the ability to apply the mathematical knowledge to some specific and daily practical situations, i.e. the development of mathematical literacy (Figure 1) (Turner, 2011).

Therefore, according to competency based education model, students have to demonstrate they are able to apply acknowledge they had been obtained. The integration of different competencies is not an easy issue where the mathematics is involved in the teaching-learning process. The proposal hypothesis is: students that understand the basic mathematical concepts are able to design and develop their own academic tools, like a calculator, and they feel more comfortable learning or even going far, teaching mathematics.

\section{Methodology}

This job was developed following a simple four step process of academic tools development (Figure 2). It starts with as here is called a traditional classroom activity, it means professor explains the topic and resolve some demonstrative problems at the blackboard. At this step a preliminary survey was done 


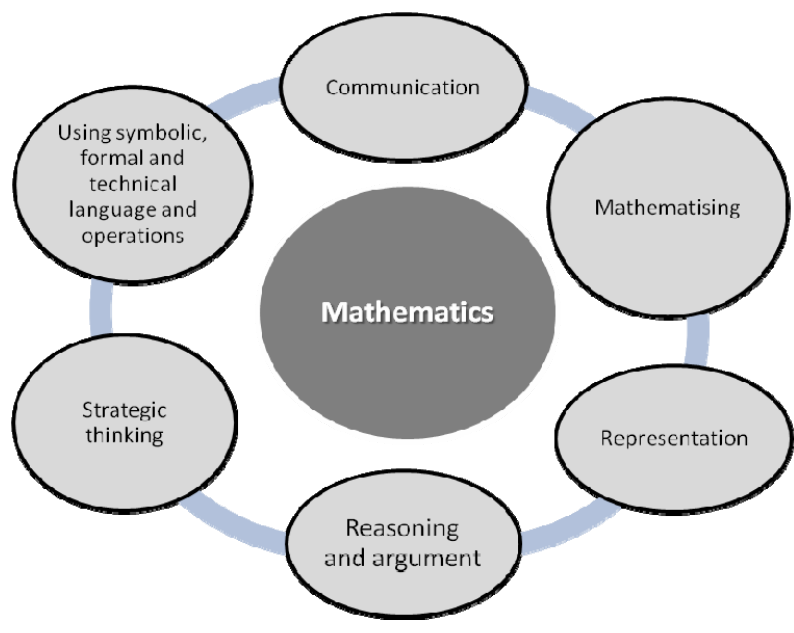

Figure 1.

Fundamental mathematical competencies.

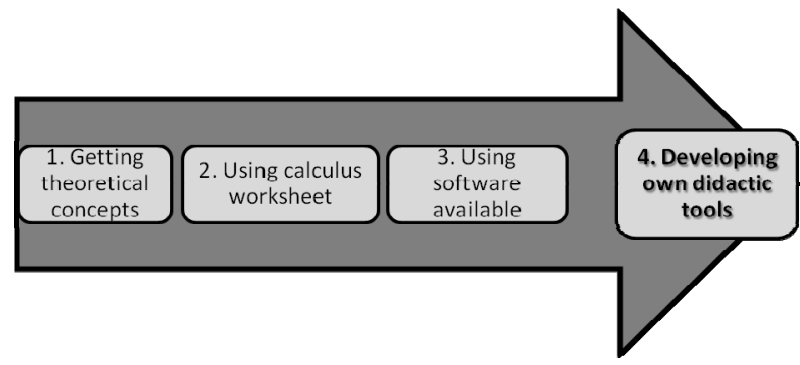

Figure 2.

Process of academic tools development.

applying a simple questionnaire to know the students feeling about mathematics.

\section{Getting Theoretical Concepts: Mathematical Basic Operations with Matrices}

At the step two, students must have kept in mind the rules to do basic operations with matrix (Sawyer, 1995):

- Every term of the matrix is given by $a_{i j}$, where $i$ is the row number and $j$ is the column number.

- For addition or subtract, both matrix must have the same order.

- For matrix multiplication, the number of columns of the first matrix must be equal to the number of rows of the second one.

$$
\begin{array}{cc}
\text { Matrix A } & \text { Matrix } B \\
m \times n & n \times q
\end{array}
$$

The order of the Resultant matrix is gotten from the numbers of rows of the first matrix and the number of columns of the second one $(m \times q)$. In this case the order of the factor affects the product.

$$
A \times B \neq B \times A
$$

The Mathematical representation of a Matrix is well described at the literature (Sawyer, 1995), this kind of representation could be one reason why students of Engineering in Information Technology, are dislike about mathematical in a general way and matrix operations in a particular way.

\section{Mathematical Basic Operations with Matrices, Using a Calculus Worksheet}

After the theoretical concepts were reviewed and used to solve academic problems, students used a calculus worksheet to develop a matrix calculator. Working on this kind of simple tools could be looks like is very easy calculus exercise, but to students must have understood all the concepts mentioned at Getting theoretical concepts section. Students must develop the exercise at their notebook, and compare with the results on the worksheet to identify errors or if the calculator really works. This is a very important step since students must to understand the role of every cell, which can contains just a number, or a data or a string or information in general. The importance of matrix in mathematics and software development in general, was deep understood, after the exercise, and they are able to identify possible applications or as this case, design and develop academic tools, for their own benefit or future generations.

\section{Results}

At the first step of the step one of process shown in Figure 2, a preliminary survey was done applying a simple questionnaire to know the students feeling about mathematics. The results show that just a few students think mathematics is related with their engineering field (Figure 3).

Two from six groups were selected to work under the proposal, what are represented by 60 out of 180 students, belongs to All part of Figure 3. Just $8.33 \%$ of 180 students think Mathematics are related to Engineering in Information Technology. Before the proposal test concept was done, just $8.33 \%$ tough that Mathematics are related to Engineering in Information Technology, after that $80 \%$ of students change their mind, data from the two experimental groups. Students develop some calculus on a basic matrix calculator, to corroborate they understand the procedure to do three basic mathematics operations with matrix (Figure 4). And they are able to identify if there are some calculus errors. A comparison for some preliminary results about student's notes in average was done (Table 1), scale 0 to 10 .

The results from software work are shown in Figures 4-6. The mathematical knowledge application started with a calculus worksheet (Figure 4).

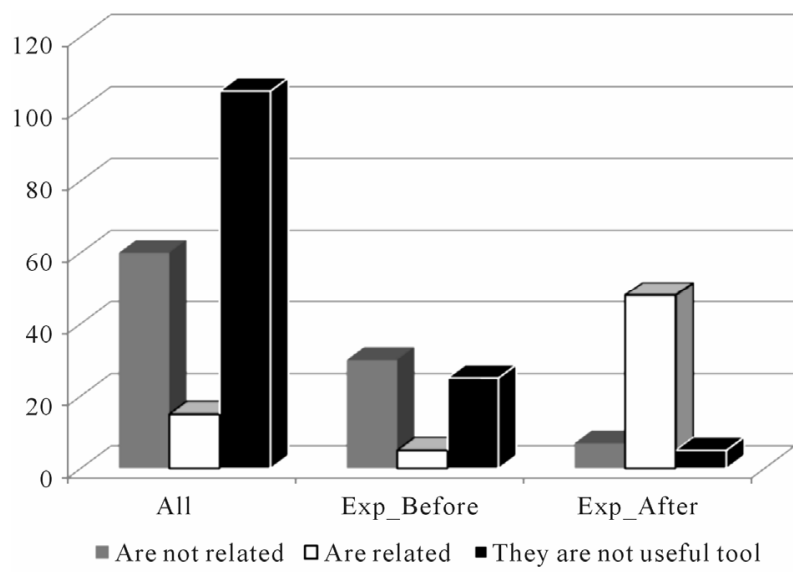

Figure 3.

Students feel about mathematics. 
Table 1.

Preliminary comparison about notes.

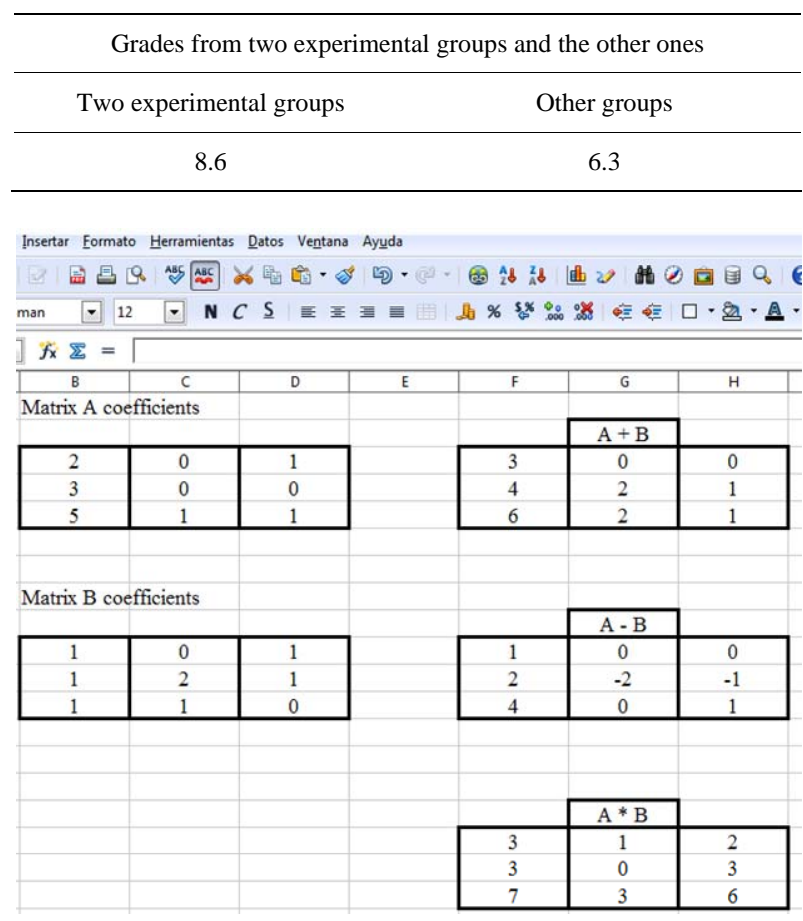

Figure 4.

Matrix calculator developed on a calculus worksheet.

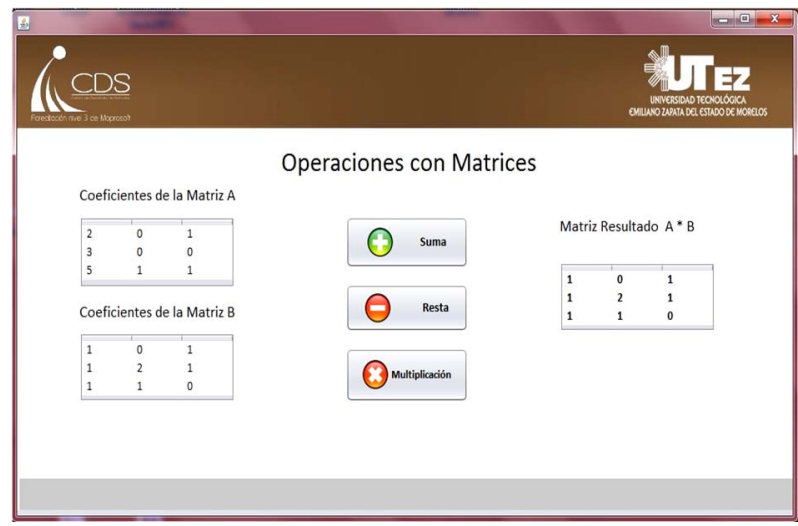

Figure 5.

Matrix calculator developed on a java application.

Students have built a simple matrix calculator integrating their Mathematical literacy and basic software handling skills. At this step students are able to detect themselves if there are some doubts about mathematical concepts of matrix operations. Next step consist of the designing and developing of own software tools that can be used as academic help (Figure 5). Students of Engineering in Information Technology study telecommunications and signal processing as part of their career sometimes they have to use a kind of specialized software, like LabVIEW (Figure 6). Handling this kind of software could be

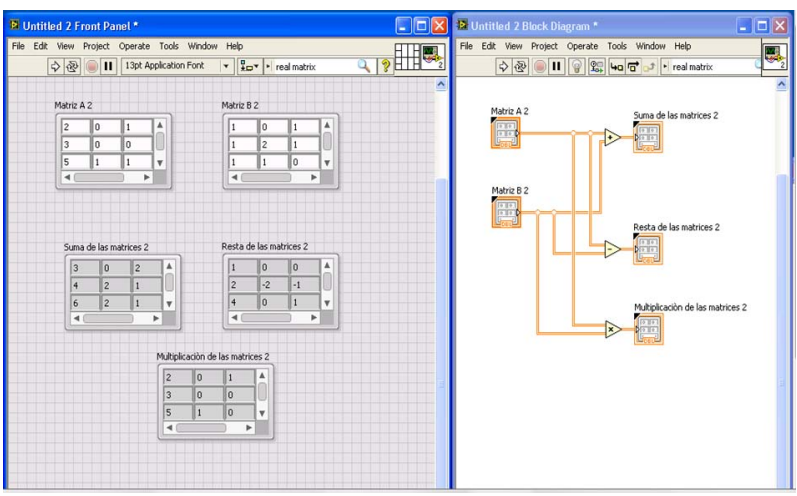

Figure 6.

Matrix calculator developed on LabVIEW software.

not an easy task, students that work under the proposal scenario, face fewer problems compared with the other group, since the operations procedure point of view.

\section{Conclusion}

Students working understood Mathematics concepts and calculus procedure using available software got understood in a deeply way, and therefore they changed their mind about Mathematics and their career. Under this scenario, students could get the fundamental competencies about Mathematics easier. Some working academic tools were developed in LabVIEW software and Java platform. The results showed that students felt more comfortable to learn or even further, to teach mathematics. Some other works related to this kind of proposal had been done with similar successful results (Salinas, 2013).

\section{Acknowledgements}

Authors want to thank students of UTEZ, for their commitment about their work to support this proposal, and the dare to put hands on about mathematics academic tools development for future generations inside the UTEZ campus.

\section{REFERENCES}

Devlin, K. (1996). Mathematics: The science of patterns. New York: Freeman.

Devlin, K. (1998). The language of mathematics, making the invisible visible. New York: Holt Paperback.

Latina, T. A. (2007). Tuning América Latina.

http://tuning.unideusto.org/tuningal/

Salinas, O. (2013). Physical concepts about telecommunications theory focusing on the application of knowledge. In press.

Sawyer, W. (1995). A prelude to mathematics. Harmondsworth, Meddlesex: Pinguin Books.

Turner, R. (2011). http://research.acer.edu.mx.au/resdev/Vol24/iss/24/5

Wittman, E. C. (2000). Institut de researche sur'l enseignement des mahtématiques.

http://irem.u-strasbg.fr/php/publi/annales/sommaires/11/WittmannA. pdf 